\title{
Studies on the Optimization and Development of Functional Instant Kodo Millet Based Porridge Mix
}

\author{
Durga Shankar Bunkar ${ }^{1}$, Pragya Bharti ${ }^{1}$, Kamalesh Kumar Meena ${ }^{3 *}$, \\ S. K. Goyal ${ }^{2}$ and V. K. Paswan ${ }^{1}$ \\ ${ }^{1}$ Department of Dairy Science and Food Technology, ${ }^{2}$ Department of Farm Engineering, \\ Institute of Agricultural Sciences, Banaras Hindu University, Varanasi, India \\ ${ }^{3}$ Department of Dairy and Food Microbiology, College of Dairy and Food Technology, \\ Maharana Pratap University of Agriculture and Technology, Udaipur, India
}

*Corresponding author

\section{A B S T R A C T}

\begin{tabular}{l} 
K e y w o r d s \\
$\begin{array}{l}\text { Kodo Millet, Instant } \\
\text { Porridge Mix, } \\
\text { Response Surface } \\
\text { Methodology, } \\
\text { Texture profile } \\
\text { analysis, Proximate } \\
\text { analysis, Shelf life }\end{array}$ \\
\hline Article Info \\
$\begin{array}{l}\text { Accepted: } \\
\text { 12 August } 2020 \\
\text { Available Online: } \\
\text { 10 September } 2020\end{array}$ \\
\hline
\end{tabular}

Keywords

Kodo Millet, Instant Porridge Mix, Response Surface Methodology, Texture profile analysis, Proximate

\section{Introduction}

Porridge is a convenient food for weaning infants, elderly and convalescents due to easy digestibility. It can be used as convenience foods, ready-to-eat or ready-to-serve foods and ready mixes, considering people's lifestyle. Porridge (dalia) is a significant North India breakfast cereal produced from cracked wheat by boiling in milk or water and is consumed with added salt or sugar. For breakfast, Porridge is an easy and staple dish (Teangpook and Paosangtong, 2011). It is generally consumed hot for breakfast and can be cooled or frozen for subsequent use (Gamel et al., 2013). Porridge enjoys resurgence as a good breakfast meal in modern societies. It is also very useful food for military troops as it can be produced to be light in weight and long in shelf-life which 
makes it convenient for operational pack rations (Khan et al., 2014) and in the case of food emergency situations. In developing nations, traditional porridges are based on local staple cereals (wheat, rice, millet, sorghum, corn) and starchy tubers (cassava, potato and plant). Two kinds of porridges ready for consumption can be differentiated depending on the percentage of cereals and fluid i.e. dense and thin porridges. Thick porridges are solid-like and can be eaten with spoon or hand whereas thin porridge or gruel is consumed by drinking as having fluid or semi-fluid consistency (Moussa et al., 2011). Typically, thin porridge is used as an additional meal for babies. The use of kodo millet was rarely done for making the porridge mix.

Millet is a generic term applied to a heterogenous group of small seeded cereal crops which are known for their small coarse grains (Weber and Fuller, 2006). Kodo millet (Paspalum scrobiculatum) belongs to the Poaceae family and is also known as cow grass, ditch millet. Kodo millet is cultivated mainly in India and Madhya Pradesh ranks first in Kodo millet cultivation in the country. It contributes about $50 \%$ area and $35 \%$ production of total millet in the country. It is a very hardy crop and drought tolerant. Kodo millet grain ranges in color from light red to dark gray and is covered in a husk which is hard to remove. Kodo Millet is rich in vitamins, minerals, amino acids and phytochemicals containing sulfur, so it is called "nutricereals", but it is deficient in tryptophan amino acid. Kodo millets are rich in vitamin B3, vitamin B6 and folic acid as well as minerals such as calcium, potassium, magnesium and zinc. Kodo millet grain contains 8.3 per cent protein in which major protein is glutelin (Sudharshana et al., 1988). It contains high amount of crude fiber (9\%) as compared to wheat $(1.2 \%)$. It provides 353 Kcal energy per $100 \mathrm{~g}$ of grains. Kodo millet contains $66.6 \%$ carbohydrate, $2.4 \%$ minerals, $1.4 \%$ fat and $2 \%$ ash. The range of iron content in Kodo millet is 25.86 ppm to 39.60 ppm (Chandel et al., 2014). Kodo millet is very easy to digest due to higher amount of lecithin, which is good for functioning of the nervous system. Regular use of Kodo millet is very useful for postmenopausal females with indications of cardiovascular disease such as high blood pressure and high level of cholesterol (Malathi et al., 2012). Kodo millet is found to useful in curing asthma, migraine, blood pressure, heart attack, atherosclerosis, and diabetic heart diseases.

Today, food processing technology has allowed the manufacturing of "ready-made" porridges that do not require lengthy preparation and are suitable for use. Mixing rice and sorghum, garlic and pigeon peas were used to produce a cereal-based porridge (Kanu et al., 2009). Freeze drying was used to make rice porridge simple to rehydrate (Rhim et al., 2011). Helland et al., (2002) produced porridge from maize grain by adding sprouted flour to unsprouted flour. Nicole et al., (2010) worked through the extrusion cooking method on ready-made composite porridge flours made from soy-maize-sorghum-wheat blends.

Instant food mix where it is premixed in some of the ingredients, in the developed world, the idea of these foods has been common for a long time. There has been a latest opening on the Indian market. Due to altering food habits and people's lifestyles, convenience foods, ready-to-eat or ready-to-serve foods and ready mixes, particularly in urban regions, have attained popularity. The Indian packaged food industry is anticipated to achieve a value of $\$ 30$ billion by 2015 , compared to currently $\$ 15$ billion. The large rise in the packaged sector will also include products that are becoming increasingly demanding. Traditional procedures of preparing various milk foods are often inconvenient and time- 
consuming (Kadam et al, 2011). This also makes immediate mixes preferable for such preparations. Therefore, instant mix products need to be developed to satisfy their demand in urban regions where it is inconvenient to prepare them using traditional techniques.

Response surface methodology (RSM) has been widely applied to develop and optimize the processing parameters of various ready-toeat and instant mixes. High protein bread with acceptable quality was developed using RSM (Henselman et al., 2006). The millet enriched biscuits developed and optimized on textural and overall acceptability using RSM technique (Chakraborty et al., 2011). A pearl millet based 'ready-to-constitute' kheer mix powder was developed and optimized on overall acceptability and desirability index by use of RSM (Bunkar et al., 2014).

The present investigation will be carried out to develop and optimize Kodo millet based instant porridge mix having good textural properties and overall acceptability, which had longer shelf life at ambient temperature. It could be new value added product for dairy and food industry with improved health benefits for consumers.

\section{Materials and Methods}

The study was carried out in the "Centre of Food Science and Technology", Institute of Agriculture Science, Banaras Hindu University, Varanasi. The ingredients used for preparation of instant dry mix were Kodo millet, stevia and skim milk powder. Kodo millet (Paspalum scrobiculatum) was purchased online from Amazon, India. Stevia (Stevia rebaudiana) was procured from local market of Lanka, Varanasi, UP, India. Skim milk powder (AMUL) was procured online from Amazon, India. Low density polyethylene (LDPE) of thickness $75 \mu \mathrm{m}$ was selected for packaging.

\section{Manufacturing Process of instant dry mix porridge}

Kodo millet grains were cleaned and washed with water twice. Thereafter, these grains were soaked in water for $4 \mathrm{hrs}$. After soaking, the grains were spread in tray of $1 \mathrm{~cm}$ thick layer and allowed for autoclaving (TOMY SX-500, Japan) at $121^{\circ} \mathrm{C}$ for $15 \mathrm{~min}$. Autoclaving/ steaming was done to soften the grains as it was to be used for the preparation of a ready- to reconstitute products. Before incorporating in the dry mix, steamed cooked grains were subjected to hot air drying in tray dryer at $45^{\circ} \mathrm{Ctill}$ desired moisture content $(\sim 8 \%)$ obtained. Then dried Kodo millet, stevia, skim milk powder were mixed properly. The process flow chart for the manufacture of instant porridge mix from Kodo millet is given in fig. 1 and various combinations used for optimization is given in table 1.

\section{Packaging of instant dry mix porridge}

$50 \mathrm{~g}$ dry mix was separately filled into individual pouches. A semi-automatic heat sealing machine (Sun Ray Industries Pvt. Ltd. Mysore, India) was used for the sealing of pouches. The sealing machine was maintained at 8 bar pressure for 8 seconds for sealing of each pouch. $50 \mathrm{~g}$ of the products were packed in $11 \times 16 \mathrm{~cm}$ LDPE pouches of $75 \mu \mathrm{m}$ thickness and stored in incubator at different temperature $8^{\circ} \mathrm{C}, 25^{\circ} \mathrm{C}, 37^{\circ} \mathrm{C}$ for checking the shelf- life.

\section{Reconstitution of packed porridge mix}

Potable water was boiled in a pan and the content of one pouch approx (35 g) was added to it in the ratio of 1:5 (dry mix: water). Temperature of water was maintained at $90^{\circ} \mathrm{C}$ for 10 minute or till desired consistency was obtained; the product was gently stirred properly during the cooking process. The 
reconstituted product was allowed to cool at $25^{\circ} \mathrm{C}$ and subjected for its textural studies and sensory evaluation.

Proximate analysis of the optimized products

The different physico-chemical properties of kodo millet based prroidge mix were analyzed. The fat content of product was estimated by using Soxhlet (AOAC, 1995). Kjeldhal method described by Dickinson (1958) was used for protein content analysis. The ash and moisture content of instant porridge mix was estimated by following the protocol of AOAC (2000). The carbohydrate content was determined by using the method of Serrem (Serrem, 2011). The crude fiber content is determined using protocol given by Van Soest and McQueen (1973). The chemical used in this study were analytical grade. All analysis was performed in triplicate.

\section{Texture Profile Analysis (TPA)}

Instant porridge mix was analyzed for different textural characteristics like consistency, cohesiveness, gumminess and chewiness using a texture analyzer (Stable Micro System, Model TA-XT Plus, UK). In this experiment, a Back extrusion rig (A/BE $35 \mathrm{~mm}$ disc) was used as a probe. The product was subjected to compressive force by probe up to the distance of $15 \mathrm{~mm}$ two times. Temperature of samples during textural analysis was maintained at $25^{\circ} \mathrm{C}$. For each evaluation, $60 \mathrm{~g}$ sample was used during texture analysis.

The conditions set in the texture analyzer for measuring textural properties of Kodo millet porridge are Probe: Back extrusion rig (A/BE $35 \mathrm{~mm}$ disc), Test mode: Compression, Pretest Speed: $5 \mathrm{~mm} / \mathrm{sec}$, Test speed: $5 \mathrm{~mm} / \mathrm{sec}$, Post-test speed: $3 \mathrm{~mm} / \mathrm{sec}$, Target mode:
Distance, Distance: $5 \mathrm{~mm}$, Time: $5 \mathrm{sec}$, Trigger Force: $5 \mathrm{~g}$. The data obtained in the compression test were used for determination of the textural parameters i.e. cohesiveness, adhesiveness, springiness, gumminess, and chewiness.

\section{Antioxidant activity}

Determination of antioxidant activity of sample was done by DPPH inhibition method (Nishino et al., 2000).

\section{Sensory evaluation}

Kodo millet based porridge was analyzed for different sensory characteristics like Color and Appearance, Body and Texture, Sweetness, Consistency, Overall acceptability. Sensory evaluation was performed by a panel of 5 semi-trained judges from Centre of Food Science and Technology, Banaras Hindu University, Varanasi. Sensory evaluation was done at $25^{\circ} \mathrm{C}$. Hedonic rating (9-point scale; 1 = dislike extremely, $9=$ like extremely) (Amerine et al., 1965) was used for color and appearance, body and texture, sweetness, consistency, overall acceptability scores.

\section{Storage Studies of instant dry mix porridge}

Instant porridge mix in LDPE pouches stored in three different temperature $8^{\circ} \mathrm{C}, 25^{\circ} \mathrm{C}, 37^{\circ} \mathrm{C}$ and samples withdrawn at an interval of 7 days for analysis up to 30 days. The stored product analyzed for free fatty acids (FFA) using the method prescribed by (Deeth et al., 1975). The extent of oxidation of fat in Kodo porridge was measured in terms of Thiobarbituric Acid (TBA) value by using the method of (Zeb and Ullah, 2016). Total hydroxy-methyl furfural (HMF) in Kodo millet porridge was done by the method recommended by (Keeneyand Bassette, 1959) with slight modification. 


\section{Microbial analysis}

The total plate count (TPC) for the product is determined using the plate count agar (Hi Media, Mumbai, India) after incubating the plates for 48 hours at $37^{\circ} \mathrm{C}$ in appropriate dilutions. The coliform counts were enumerated using and violet red bile agar (HiMedia, Mumbai, India) after incubation for $24 \mathrm{~h}$ at $30^{\circ} \mathrm{C}$. The yeast and molds were estimated with the help of potato dextrose agar (PDA, HiMedia, Mumbai, India) after incubation at $25^{\circ} \mathrm{C}$ for $4-5$ days.

\section{Results and Discussion}

The present study was undertaken with the objective to optimize the process for instant porridge using Kodo millet and skim milk powder. In the initial stages of study preliminary trials were conducted. Later the levels were optimized using response surface methodology (RSM), which evaluates individual and interactive effects of independent variables. Each of the individual response was analyzed to measure its variability with independent process variables. Analysis of Variance (ANOVA) was performed for each response to assess the suitability of the selected model.

Optimization of the process of instant porridge mixusing Kodo millet and skim milk powder

The production process of Kodo millet porridge was optimized with the help of response surface methodology (RSM). Response Surface Methodology using Minitab 18 software was used to optimize the final product using 2 variables viz., Kodo millet (25-45gm), skim milk powder (35-50 $\mathrm{gm})$. The experimental design for analysis and optimization of Kodo based porridge is given in table 2. Total 13 formulations were prepared using different level of variables.
The responses measured in instant porridge were sensory and textural characteristics. The main aim of the study is to develop gluten free and fiber rich product for the gluten intolerant patients. Keeping all the responses in range, numerical optimization technique was applied using RSM Minitab 18 for which the data is shown in table 3 . The composite desirability of the optimized product was found 0.840317 which is shown in table 4 . Optimization plot for the Kodo based instant porridge was plotted.

\section{Sensory evaluation}

Interactive effect of Kodo millet and skim milk powder on color and appearance of porridge

The maximum and minimum values for color and appearance were 7.79 and 5.17 respectively. The maximum score for color and appearance was obtained from trial no. 1 and minimum score was obtained from trail no. 13. The levels of Kodo millet and skim milk powder in trial no. 1 where $25 \mathrm{gm}$ and $35 \mathrm{gm}$ respectively.

The trial no. 13 had level of Kodo millet and skim milk powder as $35 \mathrm{gm}$ and $42.5 \mathrm{gm}$ respectively. It can be notice from equation 1 that interactive effect of Kodo millet and skim milk powder had positive effect on color and appearance. From the response surface plot (Figure 2), it can be observed that when we increase the amount of skim milk powder, the color and appearance score also decreases upto point $45 \mathrm{gm}$. Then after it was increase gradually. The value of color and appearance gradually increases upto $40 \mathrm{gm}$ of Kodo millet, then after it increase rapidly.

Color and Appearance $=34.2-0.511 \mathrm{KM}-$ $0.924 \mathrm{SMP}+0.00296 \mathrm{KM}^{*} \mathrm{KM}+0.00797$ SMP*SMP +0.00713 KM*SMP........(1) 
Where, $\mathrm{KM}=$ Kodo millet, SMP $=$ Skim milk powder

Interactive effect of Kodo millet and skim milk powder on body and texture of porridge

The maximum and minimum values for body and texture were 7.0 and 5.35 respectively. The maximum score for body and texture was obtained from trial no. 5 and minimum score was obtained from trial no.12. The level of Kodo millet and skim milk powder in trial no. 1 were 20.85 and 42.5 gm respectively.

The trial no. 12 had level of Kodo millet and skim milk powder as 35 and $42.5 \mathrm{gm}$ respectively. It can be noticed from equation 2 that interactive effect of Kodo millet and skim milk powder had negative effect on body and texture. From the response surface plot (Figure 3), it can be observed that the value of body and texture increases very slowly upto $40 \mathrm{gm}$ of skim milk powder then after it decreases. Higher amount of skim milk powder has a constant or no effect on the body and texture of porridge. The value of body and texture increases very slowly upto $40 \mathrm{gm}$ of Kodo millet then after it decreases rapidly.

Body \& Texture $=14.80-0.114 \mathrm{KM}-0.300$ $\mathrm{SMP}+0.00276 \mathrm{KM}^{*} \mathrm{KM}+0.00463$ SMP*SMP $-0.00257 \mathrm{KM} *$ SMP ........(2)

\section{Interactive effect of Kodo millet and skim milk powder on sweetness of porridge}

The maximum and minimum values for sweetness were 8.9 and 7.8 respectively. The maximum score for sweetness was obtained from trial no. 3 and minimum score was obtained from trail no.1. The level of Kodo millet and skim milk powder in trial no. 3 were 25 and $50 \mathrm{gm}$ respectively. The trial no. 1 had level of Kodo millet and skim milk powder as 25 and $35 \mathrm{gm}$ respectively. It can be notice from equation 3 that interactive effect of Kodo millet and skim milk powder had positive effect on sweetness.

From the response surface plot (Figure 4) it can be notice that the value of sweetness increases gradually upto $45 \mathrm{gm}$ of skim milk powder then after it decreases. Higher amount of skim milk powder has a constant or no effect on the body and texture of porridge. The value of sweetness increases very slowly upto $30 \mathrm{gm}$ of Kodo millet, after it decreases. Higher amount of Kodo millet has a constant or no effect on the sweetness of porridge.

Sweetness $=9.5-0.196 \mathrm{KM}+0.040 \mathrm{SMP}+$ $0.00181 \mathrm{KM}^{*} \mathrm{KM}-0.00051 \mathrm{SMP} * \mathrm{SMP}+$ $0.00080 \mathrm{KM} * \mathrm{SMP}$

\section{Interactive effect of Kodo millet and skim milk powder on consistency of porridge}

The maximum and minimum values for consistency were 8.16 and 6.6 respectively. The maximum score for consistency was obtained from trial no. 5 and minimum score was obtained from trail no.11 and 13. The level of Kodo millet and skim milk powder in trial no. 5 were 20.85 and 42.5 gm respectively.

The trial no. 11 had level of Kodo millet and skim milk powder as 35 and $42.5 \mathrm{gm}$ respectively. The trial no. 13 had level of Kodo millet and skim milk powder as 35 and $42.5 \mathrm{gm}$ respectively. It can be notice from equation 4 that interactive effect of Kodo millet and skim milk powder had negative effect on consistency. The response plot can be seen in Figure 5.

Consistency $=18.18-0.290 \mathrm{KM}-0.258$

$\mathrm{SMP}+0.00516 \mathrm{KM} * \mathrm{KM}+0.00362$ SMP*SMP $-0.00203 \mathrm{KM} *$ SMP.......(4) 
Interactive effect of Kodo millet and skim milk powder on Overall acceptability Score of porridge

The maximum and minimum values for $\mathrm{OA}$ Score were 7.52 and 6.6 respectively. The maximum score for OA Score was obtained from trial no. 1 and minimum score was obtained from trail no. 12. The level of Kodo millet and skim milk powder in trial no. 1 were 25 and $35 \mathrm{gm}$ respectively. The trial no. 12 had level of Kodo millet and skim milk powder as 35 and $42.5 \mathrm{gm}$ respectively. It can be notice from equation 5 that interactive effect of Kodo millet and skim milk powder had negative effect on OA Score. The response plot can be seen in Figure 6 .

OA Score $=19.22-0.278 \mathrm{KM}-0.362$ SMP $+0.003182 \mathrm{KM} * \mathrm{KM}+0.00395 \mathrm{SMP} * \mathrm{SMP}+$ $0.00083 \mathrm{KM} * \mathrm{SMP} \ldots . . .(5)$

\section{Texture evaluation}

Interactive effect of Kodo millet and skim milk powder on Cohesiveness of porridge

The maximum and minimum values for Cohesiveness were 253.14 and 37.28 respectively. The maximum score for Cohesiveness was obtained from trial no. 3 and minimum score was obtained from trial no. 11. The level of Kodo millet and skim milk powder in trial no. 3 were 25 and $50 \mathrm{gm}$ respectively.

The trial no.11 had level of Kodo millet and skim milk powder as 35 and $42.5 \mathrm{gm}$ respectively. It can be notice from equation 6 that interactive effect of Kodo millet and skim milk powder had negative effect on cohesiveness. The 3D Surface plot showing interactive effect of Kodo millet and skim milk powder on Cohesiveness of porridge can be seen in Figure 7.
Cohesiveness $=674+12.0 \mathrm{KM}-39.2 \mathrm{SMP}+$ $0.268 \mathrm{KM} * \mathrm{KM}+0.777 \mathrm{SMP} * \mathrm{SMP}-0.725$ $\mathrm{KM}^{*} \mathrm{SMP} \ldots \ldots .(6)$

Interactive effect of Kodo millet and skim milk powder on Adhesiveness of porridge

The maximum and minimum values for Adhesiveness were 1.450 and -88.66 respectively. The maximum score for Adhesiveness was obtained from trial no. 1 and minimum score was obtained from trail no. 8. The level of Kodo millet and skim milk powder in trial no. 1 were 25 and $35 \mathrm{gm}$ respectively. The trial no.8 had level of Kodo millet and skim milk powder as 35 and $53.1 \mathrm{gm}$ respectively. It can be notice from equation 7 that interactive effect of Kodo millet and skim milk powder had negative effect on adhesiveness. The 3D Surface plot showing interactive effect of Kodo millet and skim milk powder on adhesiveness of porridge is shown in Figure 8.

Adhesiveness $=-390-1.42 \mathrm{KM}+21.9$ SMP $+0.0451 \mathrm{KM}^{*} \mathrm{KM}-0.268 \mathrm{SMP} * \mathrm{SMP}-$ $0.047 \mathrm{KM}^{*} \mathrm{SMP} \ldots \ldots . . .(7)$

Interactive effect of Kodo millet and skim milk powder on gumminess of porridge

The maximum and minimum values for gumminess were 997.677 and 99.87 respectively. The maximum score $\mathrm{f}$ or gumminess was obtained from trial no. 3 and minimum score was obtained from trail no. 1. The level of Kodo millet and skim milk powder in trial no. 3 were 25 and 50 gm respectively. The trial no.1 had level of Kodo millet and skim milk powder as 25 and 35 gm respectively. It can be notice from equation 8 that interactive effect of Kodo millet and skim milk powder had negative effect on gumminess. The 3D Surface plot showing interactive effect of Kodo millet and skim milk powder on gumminess of porridge is shown in Figure 9. 
Gumminess $=-2416+63.1 \mathrm{KM}+64 \mathrm{SMP}+$ $0.799 \mathrm{KM}^{*} \mathrm{KM}+0.67 \mathrm{SMP} * \mathrm{SMP}-3.07$ KM*SMP.......(8)

Interactive effect of Kodo millet and skim milk powder on chewiness of porridge

The maximum and minimum values for chewiness were 739.646 and 64.886 respectively. The maximum score for chewiness was obtained from trial no. 7 and minimum score was obtained from trail no. 11. The level of Kodo millet and skim milk powder in trial no. 7 were 35 and $31.89 \mathrm{gm}$ respectively. The trial no.11 had level of Kodo millet and skim milk powder as 35 and $42.5 \mathrm{gm}$ respectively. It can be notice from equation 9 that interactive effect of Kodo millet and skim milk powder had negative effect on chewiness. The 3D Surface plot showing interactive effect of Kodo millet and skim milk powder on chewiness of porridge can be seen in Figure 10.

Chewiness $=3094+74.9 \mathrm{KM}-194 \mathrm{SMP}+$ $0.501 \mathrm{KM} * \mathrm{KM}+3.43 \mathrm{SMP} * \mathrm{SMP}-2.82$ $\mathrm{KM}^{*} \mathrm{SMP} \ldots . . .(9)$

Table.1 Different trial combinations of variables used for optimization of Kodo millet porridge

\begin{tabular}{|c|c|c|c|c|}
\hline Formulation & Kodo millet (g) & SMP (g) & Stevia (g) & Water (ml) \\
\hline C1 & 25 & 35 & 5 & 500 \\
\hline C2 & 30 & 40 & 5.5 & 650 \\
\hline C3 & 35 & 45 & 6 & 800 \\
\hline C4 & 45 & 50 & 7 & 950 \\
\hline
\end{tabular}

SMP - Skim milk powder

Table.2 Experimental design for analysis and optimization of Kodo based porridge

\begin{tabular}{|c|c|c|c|c|}
\hline Run Order & Pt Type & Blocks & Kodo millet & Skim milk powder \\
\hline $\mathbf{1 .}$ & 1 & 1 & 25 & 35 \\
\hline $\mathbf{2 .}$ & 1 & 1 & 45 & 35 \\
\hline $\mathbf{3 .}$ & 0 & 1 & 35 & 42.5 \\
\hline $\mathbf{4 .}$ & 0 & 1 & 35 & 42.5 \\
\hline $\mathbf{5 .}$ & -1 & 1 & 49.14 & 42.5 \\
\hline $\mathbf{6 .}$ & -1 & 1 & 35 & 31.89 \\
\hline $\mathbf{7 .}$ & -1 & 1 & 20.85 & 42.5 \\
\hline $\mathbf{8 .}$ & 0 & 1 & 35 & 42.5 \\
\hline $\mathbf{9 .}$ & -1 & 1 & 35 & 53.1 \\
\hline $\mathbf{1 0 .}$ & 1 & 1 & 25 & 50 \\
\hline $\mathbf{1 1}$ & 0 & 1 & 35 & 42.5 \\
\hline $\mathbf{1 2}$. & 1 & 1 & 45 & 50 \\
\hline $\mathbf{1 3}$ & 0 & 1 & 35 & 42.5 \\
\hline
\end{tabular}


Table.3 Response surface methods for optimization of sensory evaluation and texture responses obtained in different trials performed by RSM using Minitab 18 software

\begin{tabular}{|c|c|c|c|c|c|c|c|c|c|c|c|}
\hline S No. & KM & SMP & C\&A & B\&T & Sweetness & Consistency & OA Score & Cohesiveness & Adhesiveness & Gumminess & Chewiness \\
\hline 1. & 25 & 35 & 7.79 & 6.84 & 7.8 & 7.65 & 7.52 & 114.81 & 1.450 & 99.87 & 118.8 \\
\hline 2. & 45 & 35 & 6.43 & 6.73 & 8.2 & 7.66 & 7.25 & 210.20 & -1.708 & 245.819 & 193.49 \\
\hline 3. & 25 & 50 & 6.49 & 6.78 & 8.9 & 7.9 & 7.51 & 253.14 & -2.615 & 997.667 & 950.757 \\
\hline 4. & 45 & 50 & 7.27 & 5.90 & 8.1 & 7.3 & 7.14 & 131.06 & -19.723 & 223.686 & 179.245 \\
\hline 5. & 20.85 & 42.5 & 5.63 & 7.00 & 8.3 & 8.16 & 7.27 & 99.92 & -6.126 & 306.080 & 165.202 \\
\hline 6. & 49.14 & 42.5 & 6.02 & 6.01 & 8.5 & 7.73 & 7.06 & 116.21 & -5.291 & 112.600 & 97.760 \\
\hline 7. & 35 & 31.8 & 5.89 & 6.08 & 8.3 & 7.74 & 7.00 & 131.77 & -0.978 & 132.400 & 739.646 \\
\hline 8. & 35 & 53.1 & 6.37 & 6.87 & 8.6 & 6.9 & 7.18 & 152.15 & -88.660 & 118.100 & 93.760 \\
\hline 9. & 35 & 42.5 & 5.43 & 6.13 & 8.1 & 7.2 & 6.71 & 101.28 & -4.250 & 128.123 & 69.860 \\
\hline 10. & 35 & 42.5 & 6.11 & 5.90 & 8.6 & 7.19 & 6.95 & 87.34 & -8.790 & 145.132 & 79.620 \\
\hline 11. & 35 & 42.5 & 6.31 & 6.25 & 8.2 & 6.6 & 6.84 & 37.28 & -3.725 & 163.979 & 64.886 \\
\hline 12. & 35 & 42.5 & 5.69 & 5.35 & 8.4 & 6.960 & 6.6 & 62.41 & -5.620 & 179.215 & 82.790 \\
\hline 13. & 35 & 42.5 & 5.17 & 6.32 & 8.5 & 6.6 & 6.64 & 114.95 & -2.185 & 192.146 & 75.790 \\
\hline
\end{tabular}

Table.4 Optimization of Kodo based porridge

\begin{tabular}{|c|c|c|c|}
\hline \multirow{3}{*}{ Factors } & Kodo millet & Optimized values & Desirability \\
\hline \multirow{3}{*}{ Responses } & Skim milk powder & 23.4292 & - \\
\cline { 2 - 4 } & C\&A & 53.1066 & - \\
\cline { 2 - 4 } & B\&T & 6.20222 & - \\
\cline { 2 - 4 } & Sweetness & 7.58113 & - \\
\cline { 2 - 4 } & Consistency & 8.09033 & - \\
\cline { 2 - 4 } & OA & 7.76894 & - \\
\cline { 2 - 4 } & Cohesiveness & 309.010 & - \\
\hline & Adhesiveness & -46.3347 & - \\
\cline { 2 - 4 } & Chewiness & 970.809 & - \\
\hline Composite Desirability & Gumminess & 1002.47 & \\
\hline
\end{tabular}


Table.5 Composition of the optimized product

\begin{tabular}{|l|c|}
\hline \multicolumn{1}{|c|}{ Constituents } & Amount $(\mathbf{g} / \mathbf{1 0 0 g})$ \\
\hline Protein & $5.5 \pm 1.08$ \\
\hline Fat & $0.83 \pm 0.27$ \\
\hline Moisture & $1.96 \pm 0.89$ \\
\hline Total Carbohydrate & $89 \pm 1.67$ \\
\hline Crude Fibre & $6.13 \pm 1.32$ \\
\hline Antioxidant & $72.6 \pm 4.34$ \\
\hline Ash & $2.2 \pm 0.53$ \\
\hline Data is represented as Mean \pm Standard Deviation $(\mathrm{n}=3)$
\end{tabular}

Table.6 Changes in FFA content

\begin{tabular}{|c|c|c|c|c|c|c|c|c|c|c|c|c|c|}
\hline \multirow[b]{2}{*}{ Temp. } & \multirow[t]{2}{*}{$0^{\text {th }}$ Day } & \multicolumn{3}{|c|}{$7^{\text {th }}$ Day } & \multicolumn{3}{|c|}{$14^{\text {th }}$ Day } & \multicolumn{3}{|c|}{$21^{\text {th }}$ Day } & \multicolumn{3}{|c|}{$28^{\text {th }}$ Day } \\
\hline & & $8^{0} \mathrm{C}$ & $25^{\circ} \mathrm{C}$ & $37^{\circ} \mathrm{C}$ & $8^{0} \mathrm{C}$ & $25^{\circ} \mathrm{C}$ & $37^{0} \mathrm{C}$ & $8^{0} \mathrm{C}$ & $25^{\circ} \mathrm{C}$ & $37^{0} \mathrm{C}$ & $8^{0} \mathrm{C}$ & $25^{\circ} \mathrm{C}$ & $37^{0} \mathrm{C}$ \\
\hline FFA $(\mu \mathrm{ec}$ & 123 & 0.191 & 0.242 & 0.26 & 0.219 & 0.271 & 0.29 & 0.222 & 0.294 & 0.31 & 0.248 & 0.312 & $0.36 ?$ \\
\hline
\end{tabular}

Table.7 Changes in HMF Content

\begin{tabular}{|c|c|c|c|c|c|c|c|c|c|c|c|c|c|}
\hline & $0^{\text {th }}$ Day & \multicolumn{3}{|c|}{$7^{\text {th }}$ Day } & \multicolumn{3}{|c|}{$14^{\text {th }}$ Day } & \multicolumn{3}{|c|}{$21^{\text {th }}$ Day } & \multicolumn{3}{|c|}{$28^{\text {th }}$ Day } \\
\hline Temp & & $8^{0} \mathrm{C}$ & $25^{\circ} \mathrm{C}$ & $37^{0} \mathrm{C}$ & $8^{0} \mathrm{C}$ & $25^{0} \mathrm{C}$ & $37^{0} \mathrm{C}$ & $8^{0} \mathrm{C}$ & $25^{\circ} \mathrm{C}$ & $37^{0} \mathrm{C}$ & $8^{0} \mathrm{C}$ & $25^{\circ} \mathrm{C}$ & $37^{\circ} \mathrm{C}$ \\
\hline $\begin{array}{l}\text { HMF } \\
(\mu \mathrm{mol} / 100 \mathrm{~g})\end{array}$ & 0.009 & 0.011 & 0.017 & 0.021 & 0.011 & 0.020 & 0.023 & 0.012 & 0.022 & 0.026 & 0.013 & 0.023 & 0.029 \\
\hline
\end{tabular}

Table.8 Changes in Thiobarbituric acid (TBA) content during storage

\begin{tabular}{|l|c|c|c|c|c|c|c|c|c|c|c|c|c|c|}
\hline & $\begin{array}{c}\mathbf{0}^{\text {th }} \\
\text { Day }\end{array}$ & \multicolumn{3}{|c|}{$\mathbf{7}^{\text {th }}$ Day } & \multicolumn{3}{|c|}{$\mathbf{1 4}^{\text {th }}$ Day } & \multicolumn{3}{c|}{$\mathbf{2 1}^{\text {th }}$ Day } & \multicolumn{3}{c|}{$\mathbf{2 8}^{\text {th }}$ Day } \\
\hline Temp & & $\mathbf{8}^{\mathbf{0}} \mathbf{C}$ & $\mathbf{2 5}^{\mathbf{0}} \mathbf{C}$ & $\mathbf{3 7}^{\mathbf{0}} \mathbf{C}$ & $\mathbf{8}^{\mathbf{0}} \mathbf{C}$ & $\mathbf{2 5}^{\mathbf{0}} \mathbf{C}$ & $\mathbf{3 7 ^ { \mathbf { 0 } } \mathbf { C }}$ & $\mathbf{8}^{\mathbf{0}} \mathbf{C}$ & $\mathbf{2 5}^{\mathbf{0}} \mathbf{C}$ & $\mathbf{3 7}^{\mathbf{0}} \mathbf{C}$ & $\mathbf{8}^{\mathbf{0}} \mathbf{C}$ & $\mathbf{2 5}^{\mathbf{0}} \mathbf{C}$ & $\mathbf{3 7}^{\mathbf{0}} \mathbf{C}$ \\
\hline $\begin{array}{l}\text { TBA } \\
\text { (Absorbance } \\
\mathbf{5 3 2} \mathbf{~ n m})\end{array}$ & 0.015 & 0.017 & 0.024 & 0.033 & 0.017 & 0.026 & 0.037 & 0.019 & 0.028 & 0.041 & 0.020 & 0.031 & 0.045 \\
\hline
\end{tabular}

Table.9 Changes in microbial growth

\begin{tabular}{|c|c|c|c|c|c|c|c|c|c|c|c|c|c|}
\hline & $0^{\text {th }}$ Day & \multicolumn{3}{|c|}{$7^{\text {th }}$ Day } & \multicolumn{3}{|c|}{$14^{\text {th }}$ Day } & \multicolumn{3}{|c|}{$21^{\text {th }}$ Day } & \multicolumn{3}{|c|}{$28^{\text {th }}$ Day } \\
\hline Temperature & & $8^{0} \mathrm{C}$ & $25^{\circ} \mathrm{C}$ & $37^{\circ} \mathrm{C}$ & $8^{0} \mathrm{C}$ & $25^{\circ} \mathrm{C}$ & $37^{\circ} \mathrm{C}$ & $8^{0} \mathrm{C}$ & $25^{\circ} \mathrm{C}$ & $37^{0} \mathrm{C}$ & $8^{0} \mathrm{C}$ & $25^{\circ} \mathrm{C}$ & $37^{\circ} \mathrm{C}$ \\
\hline $\begin{array}{l}\text { Total Plate } \\
\text { Count }\end{array}$ & ND & ND & ND & ND & ND & ND & ND & ND & ND & ND & ND & ND & 1.015 \\
\hline $\begin{array}{l}\text { Yeast and } \\
\text { Mold Count }\end{array}$ & ND & ND & ND & ND & ND & ND & ND & ND & ND & ND & ND & ND & ND \\
\hline $\begin{array}{l}\text { Coliform } \\
\text { Count }\end{array}$ & ND & ND & ND & ND & ND & ND & ND & ND & ND & ND & ND & ND & ND \\
\hline
\end{tabular}

ND $=$ Non Detected 
Fig.1 Process flow chart for the manufacture of instant porridge mix from kodo millet

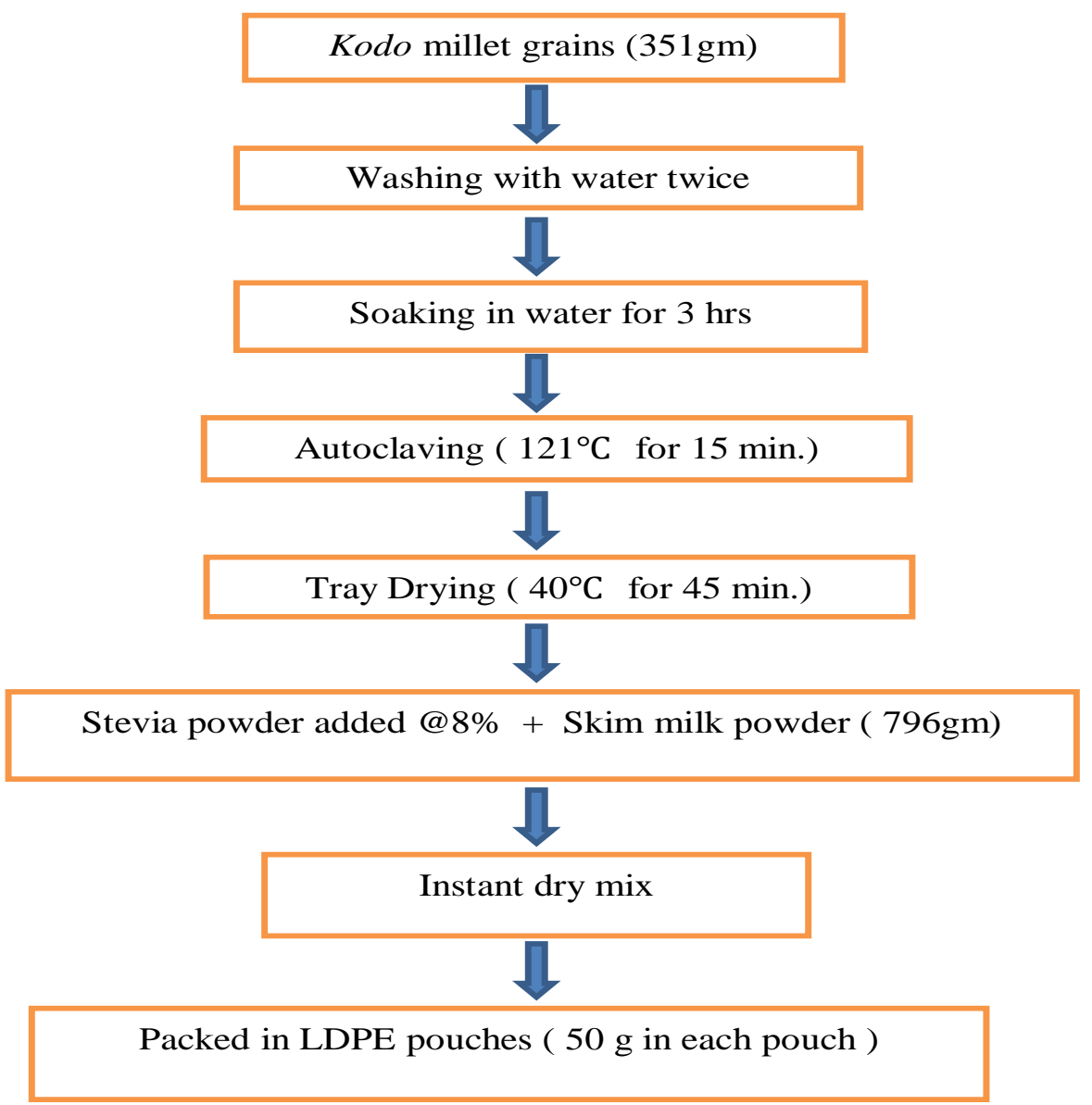

Fig.2 3D Surface plot showing interactive effect of Kodo millet and skim milk powder on color and appearance of porridge

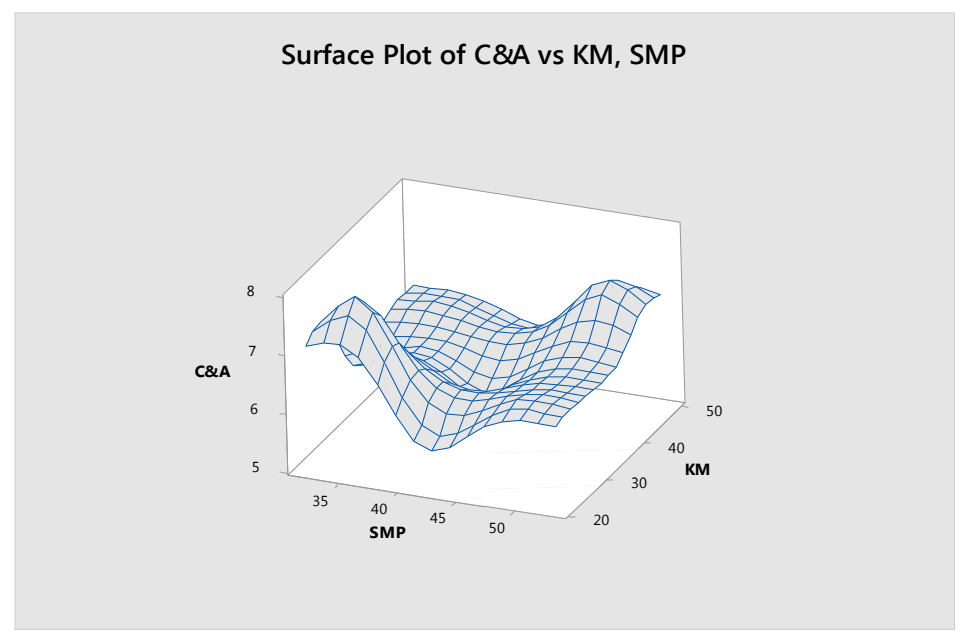


Fig.3 3D Surface plot showing interactive effect of Kodo millet and skim milk powder on Body and texture of porridge

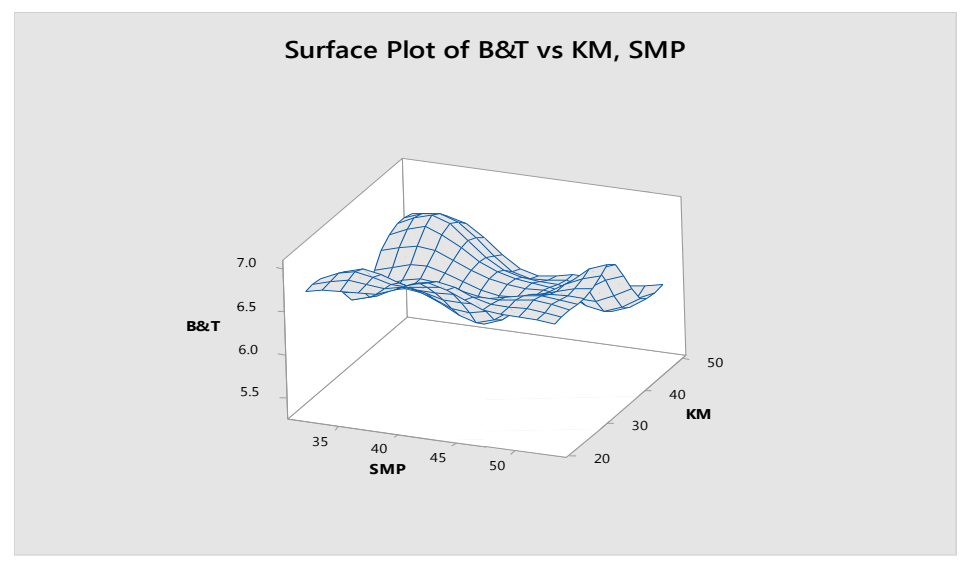

Fig.4 3D Surface plot showing interactive effect of Kodo millet and skim milk powder on sweetness of porridge

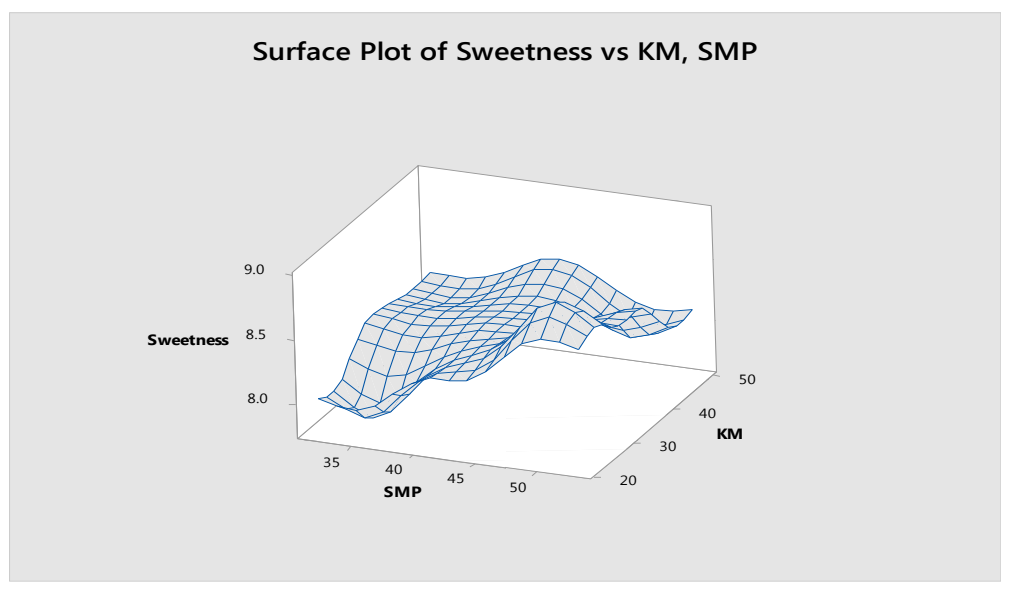

Fig.5 3D Surface plot showing interactive effect of Kodo millet and skim milk powder on consistency of porridge

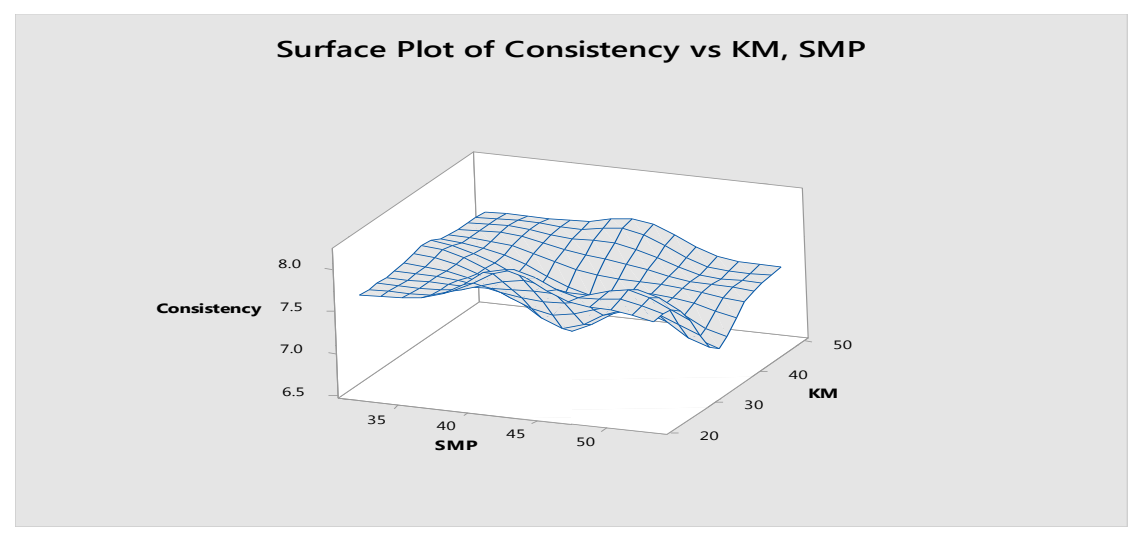


Fig.6 3D Surface plot showing interactive effect of Kodo millet and Skim milk powder on overall acceptability of porridge

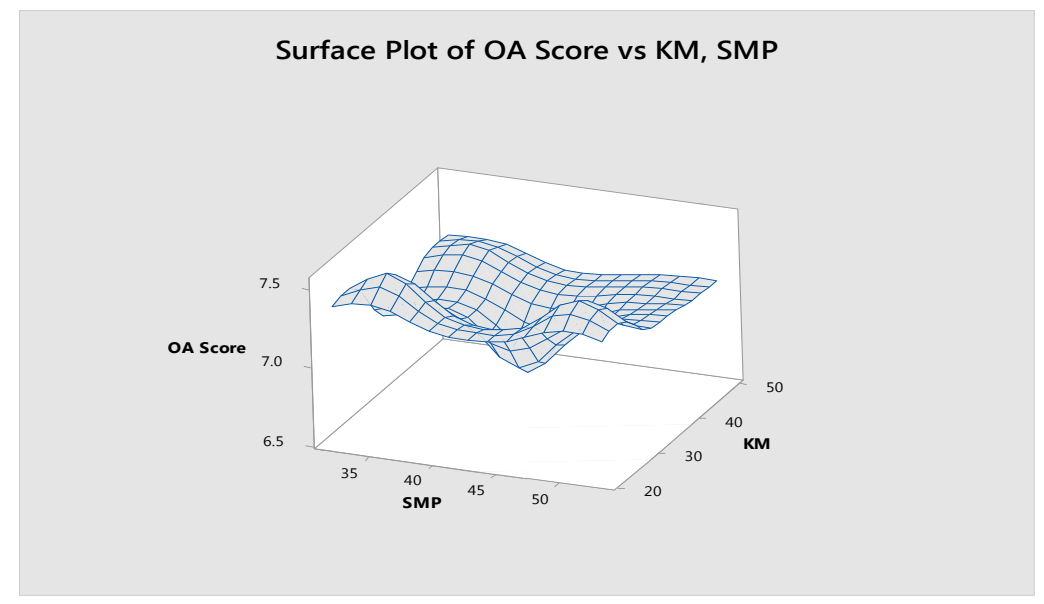

Fig.7 3D Surface plot showing interactive effect of Kodo millet and skim milk powder on cohesiveness of porridge

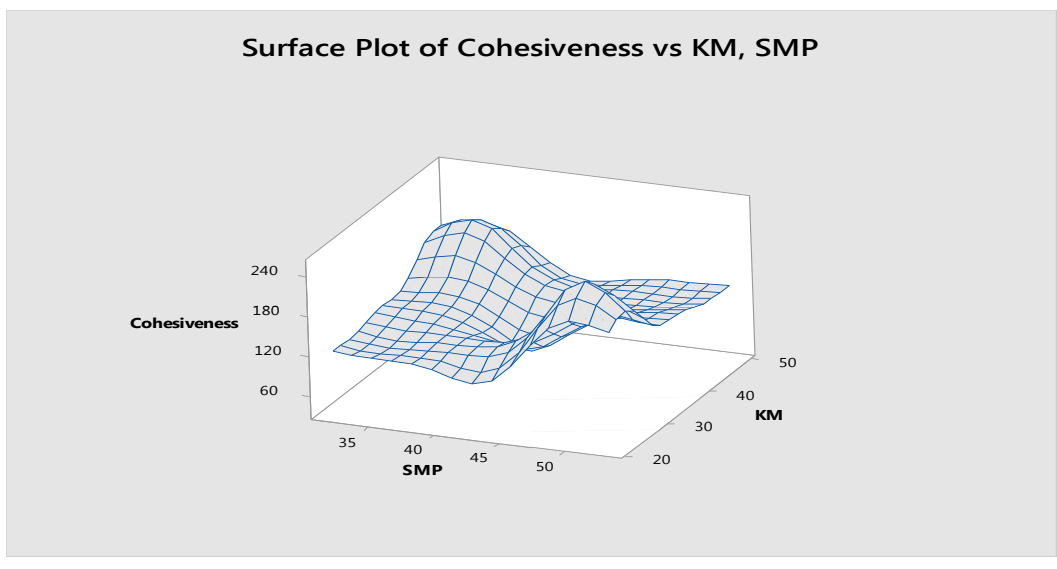

Fig.8 3D Surface plot showing interactive effect of Kodo millet and skim milk powder on adhesiveness of porridge

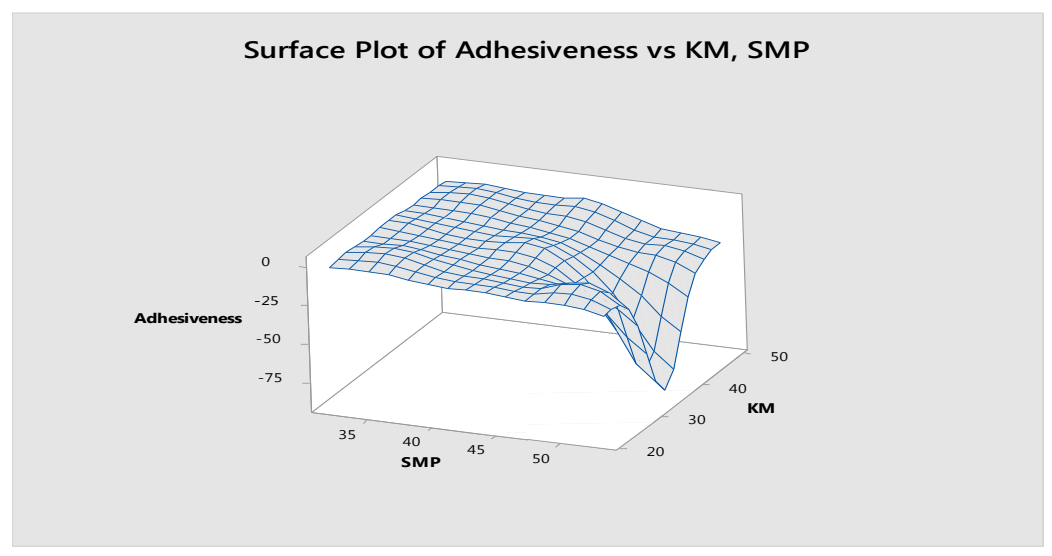


Fig.9 3D Surface plot showing interactive effect of Kodo millet and skim milk powder on gumminess of porridge

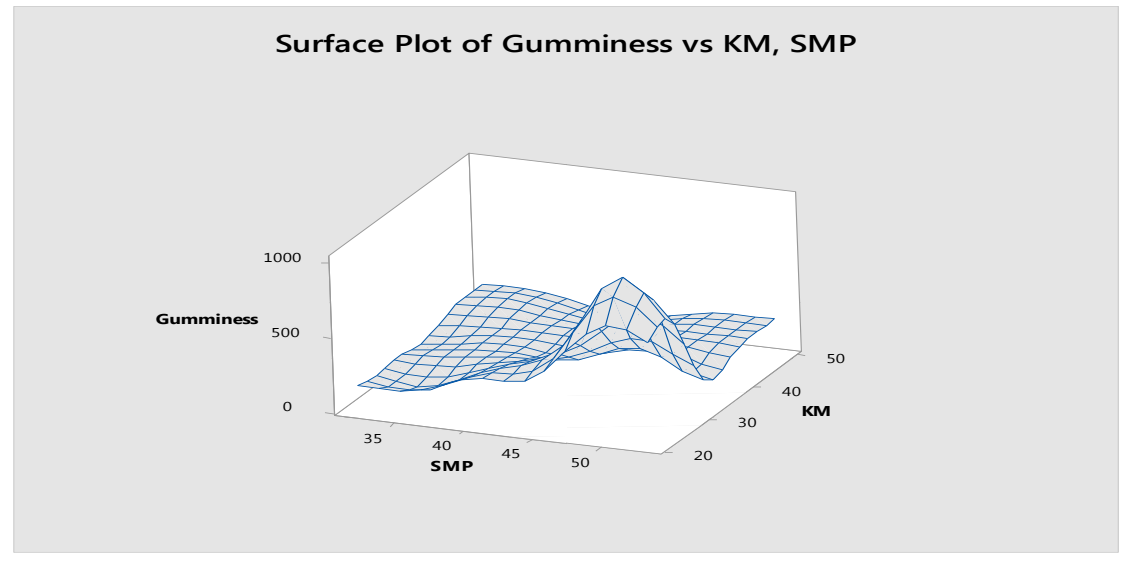

Fig.10 3D Surface plot showing interactive effect of Kodo millet and Skim milk powder on chewiness of porridge

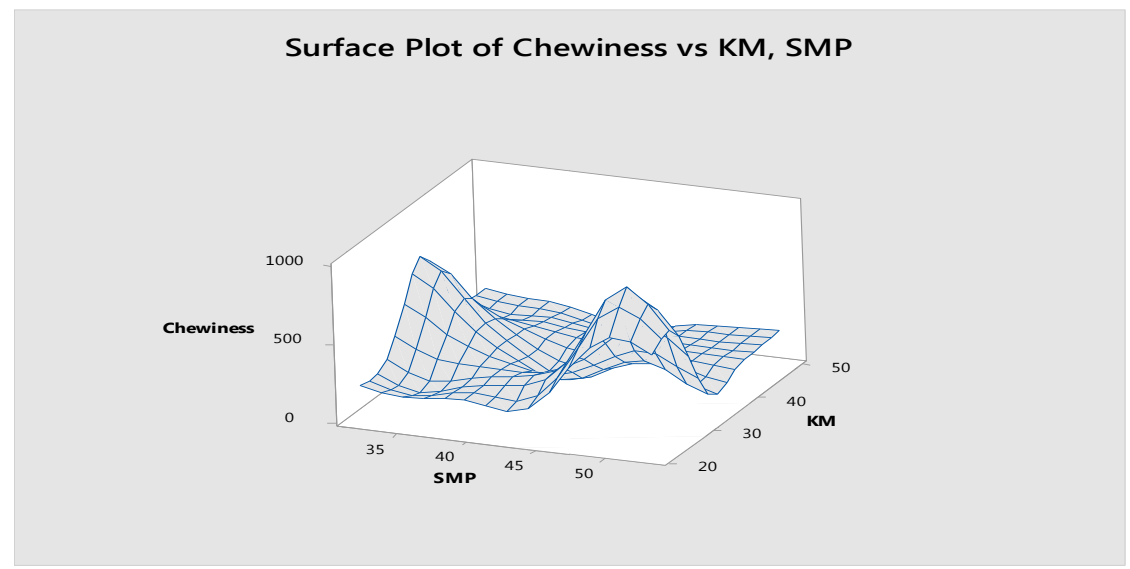

Fig.11 Optimization plot for Kodo millet based porridge
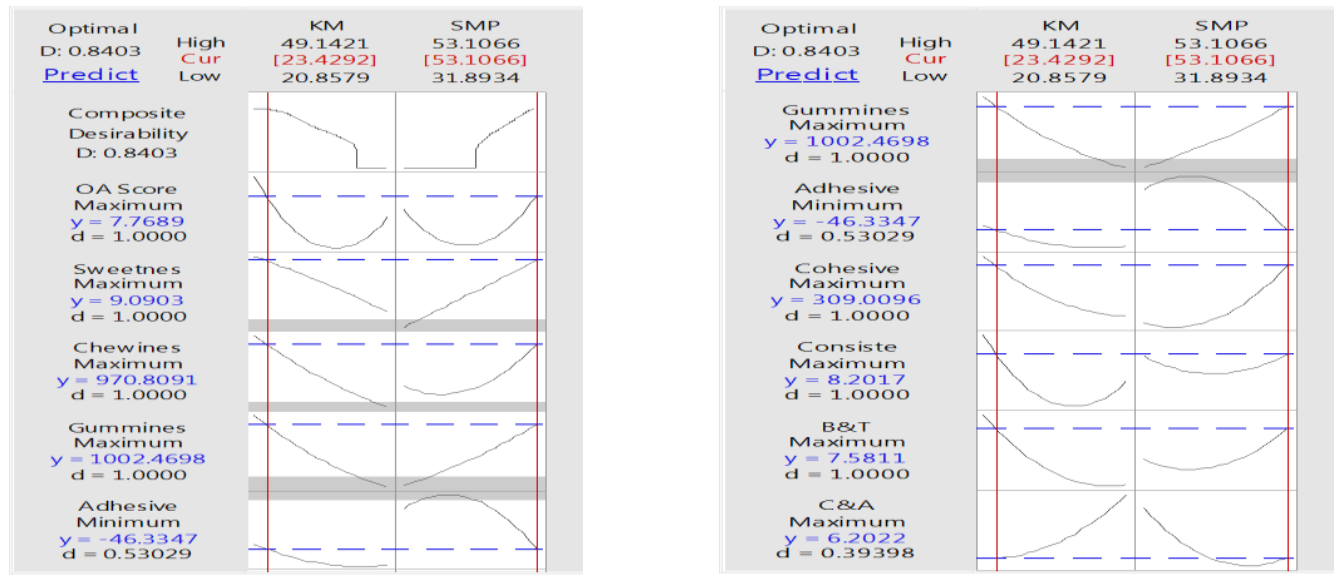
Fig.12 Changes in free fatty acid content during storage

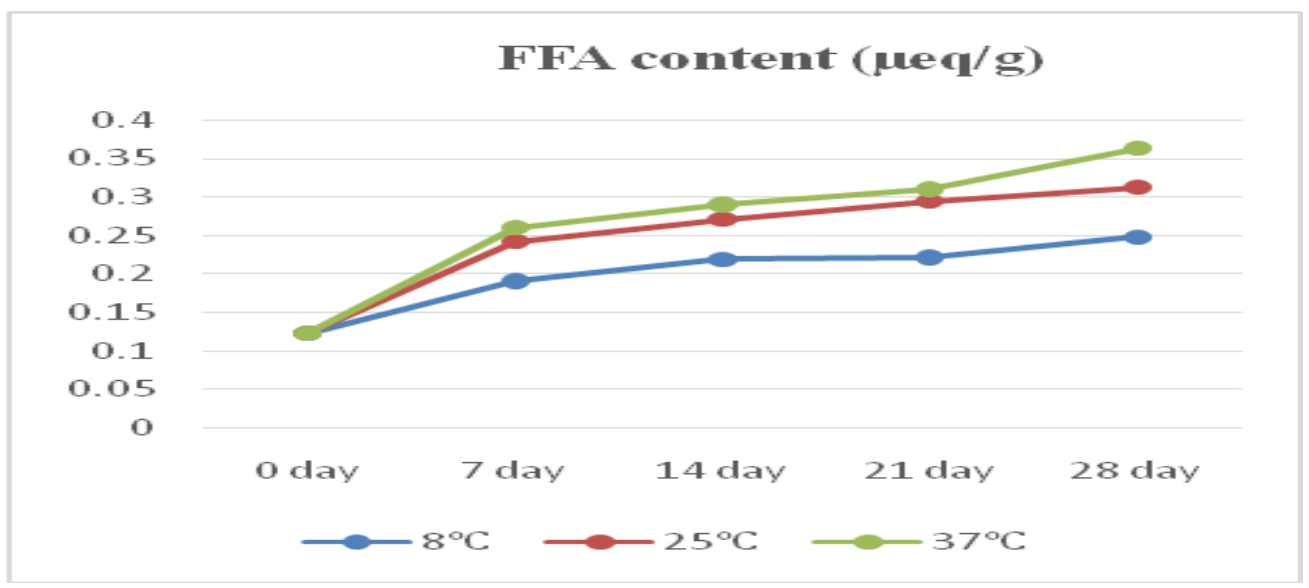

Fig.13 Changes in Hydroxy Methyl Furfural (HMF) content during storage

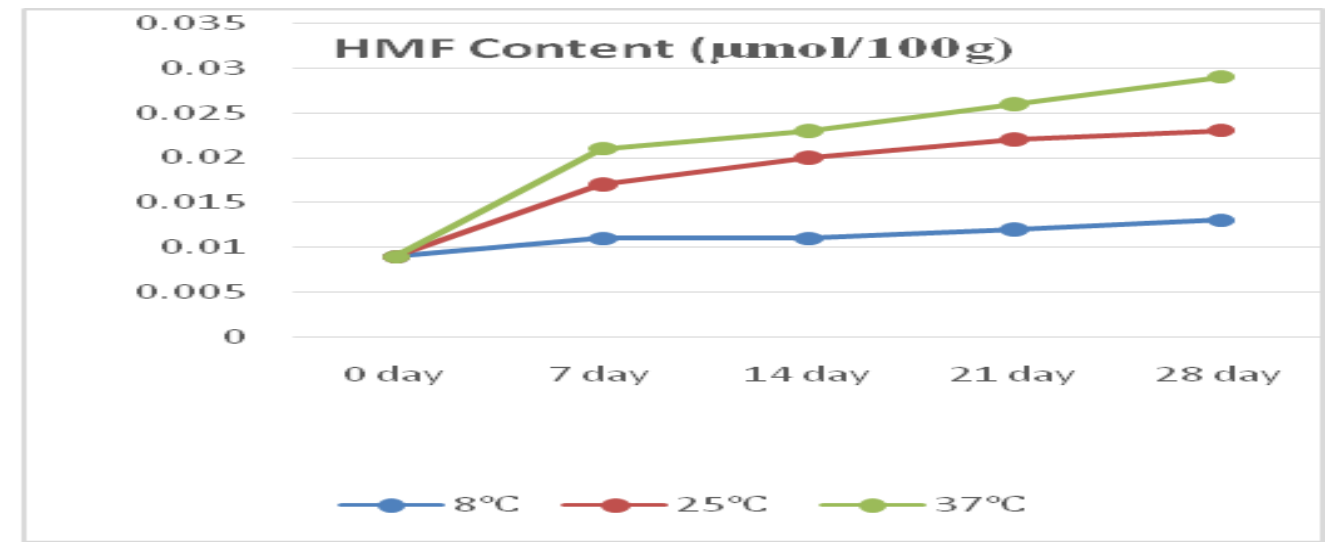

Fig14 Changes in Thiobarbituric Acid (TBA) content during storage

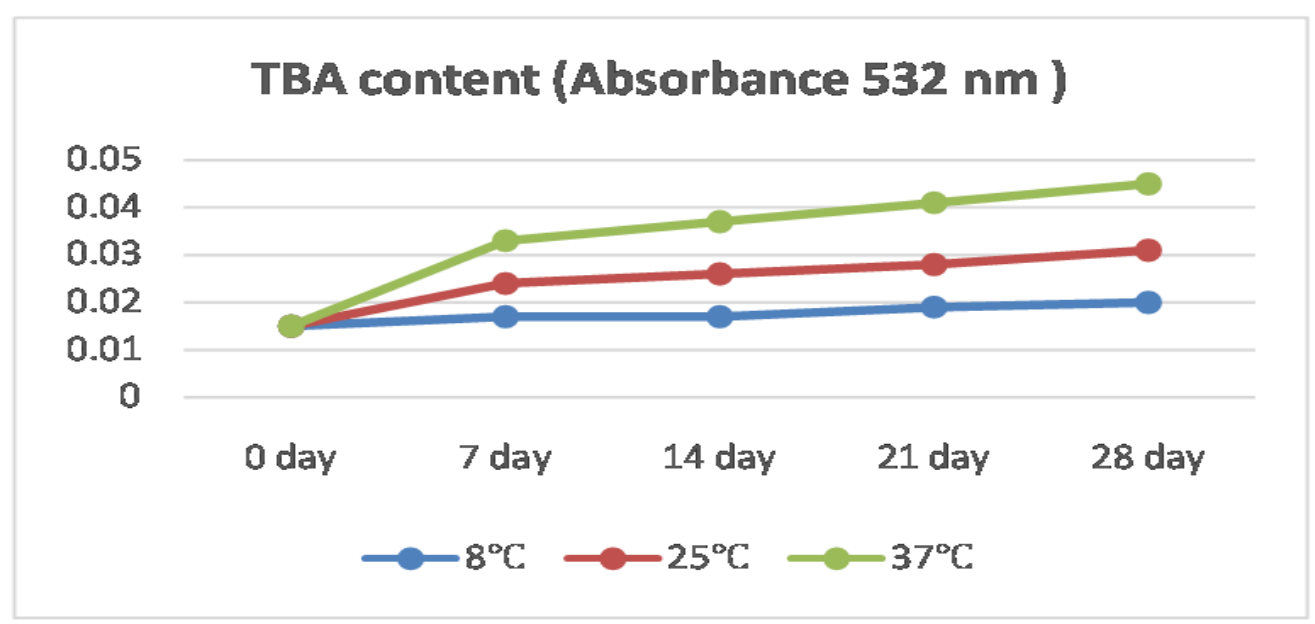


Optimization of solution and their validations

In order to arrive at the best combination of the ingredient-based variables, the optimization command of the DOE of Minitab 18 was used. The various constraints criteria for optimization are considered and the optimization goals for all the attributes differed. The method adopted for the process optimization was based on numerical method. The optimization plot for Kodo millet based porridge is given in Figure 11. The optimized product is analyzed for various components and the values for that are given in table 5 .

\section{Shelf life study of optimized instant porridge mix}

Storage study was conducted on Kodo porridge samples. The product obtained was stored in LDPE (low density polyethylene) pouches. The analysis was carried out at an interval of 7 days for 1 month and the observations were recorded. The shelf life of the product was checked at three different temperatures i.e. $8^{0} \mathrm{C}, 25^{0} \mathrm{C}, 37^{0} \mathrm{C}$.

\section{Changes in Free fatty acid content during storage}

Lipolysis is measured by FFA (Rossel, 1989). The free fatty acids content of porridge increased significantly with the progression of storage period. The release of free fat during storage and presence of moisture content could be responsible for lipolysis. A measure of the free fatty acids in a food sample gives an idea about the degree of rancidity in that particular food system. FFA formation was observed to be lesser at $8^{0} \mathrm{C}$ as compared to $25^{\circ} \mathrm{C}$ and $37^{\circ} \mathrm{C}$. It can therefore be concluded that with increase in storage time and temp. The formation of FFA increases. At $8^{0} \mathrm{C}$, $25^{\circ} \mathrm{C}, 37^{0} \mathrm{C}$ the total FFA content increased to $0.248,0.312,0.363 \mu$ eq/g respectively. The change in FFA values with respect to storage temperature is given in table 6 and Figure 12.

\section{Changes in Hydroxy Methyl Furfural (HMF) content during storage}

HMF is an organic compound resulting from dehydration of certain sugars. It is almost absent in fresh food, but it is generated naturally in sugar-containing food during heat treatment such as drying or cooking. Maillard reaction can occur during the manufacture and storage of heat-processed foods that contain sugar and amino acids and it is associated with change of color and flavor. It was observed that HMF content was lesser at $8^{0} \mathrm{C}$ as compared to $25^{\circ} \mathrm{Cand} 37^{\circ} \mathrm{C}$. This implies that HMF content increase with increase in storage time and temperature. At $8^{0} \mathrm{C}, 25^{\circ} \mathrm{C}, 37^{\circ} \mathrm{C}$ the total HMF content increased to $0.013,0.023$, and 0.029 respectively which is plotted in Figure 13. The Changes in Hydroxy Methyl Furfural (HMF) content during storage is given in table 7.

\section{Changes in Thiobarbituric acid (TBA) content during storage}

The value of TBA is commonly used in foods to estimate peroxidation and rancidity. TBA was expressed at $532 \mathrm{~nm}$ as absorbance. The formation of TBA content was noted to be lesser at $8^{0} \mathrm{C}$ as compared to $25^{\circ} \mathrm{C}$ and $37^{\circ} \mathrm{C}$. Therefore, it can be stated that the formation of TBA content increases with an increase in storage time and temperature. At $8^{\circ} \mathrm{C}, 25^{\circ} \mathrm{C}$, $37^{\circ} \mathrm{C}$, the total TBA content increased to $0.020,0.031,0.45$ respectively. The changes in thiobarbituric acid (TBA) content during storage are shown in table 8 and graphical representation shown in Figure 14.

\section{Microbial load during storage}

The microbial load during storage at three different temperatures $8^{0} \mathrm{C}, 25^{\circ} \mathrm{C}$, and $37^{\circ} \mathrm{C}$ were studied. Total plate count, yeast and 
mold and coliform count were performed for the stored product. The yeast and mold counts and coliform counts of instant dry mix porridge was found nil till the end of storage period of 30 days. Total plate count was occurred on $28^{\text {th }}$ day in sample stored at $37^{\circ} \mathrm{C}$. The microbial results for the product are shown in table 9.

In conclusion the optimized levels of Kodo millet and skim milk powder for the manufacture of the Kodo millet based Porridge mix were predicted based on Color and Appearance, Body and Texture, Consistency, Sweetness, Adhesiveness, Cohesiveness, Gumminess, Chewiness and Overall acceptability (OA) score using RSM. The present study was developed by making instant porridge of Kodo millet in which stevia and skim milk powder was added. Kodo millet is recommended for people with diabetes as they are fiber rich. Kodo millets do not contain gluten and are useful for people who are intolerant to gluten.

It is a good substitute for wheat and rice. It can be consumed at every meal- breakfast, lunch and dinner. It is clear that highly acceptable instant Kodo Porridge mix, capable of reconstitution in 4-5 $\mathrm{min}$ by putting in boiling water, can be prepared by tray drying of steamed Kodo and mixing stevia, skim milk powder with the dehydrated product. In the instant Kodo Porridge mix, significant spoilage during storage is caused by lipid autoxidation and non-enzymatic browning reactions, leading to off-flavor and brown discoloration in the stored Porridge mix samples.

\section{Conflict of interest}

The authors declare that there are no conflicts of interest in the course of conducting the research. All the authors had final decision regarding the manuscript and decision to submit the findings for publication.

\section{References}

Amerine, M.A., Pongborn, R.H. and Roescler, E.B. (1965). Principles of Sensory Evaluation of Food. New York: Academic Press; 338-339.

AOAC.(1995).Official methods of analysis 16th Ed. Association of Official Analytical Chemists. Washington DC, USA.

AOAC. (2000). Official Methods of Analysis of the Association of Official Agricultural Chemists. Association of Analytical Chemists, Washington, DC, USA.

Bunkar, D.S., Jha, A., and Mahajan, A. (2014). Optimization of the formulation and technology of pearl millet based 'Ready-To-Reconstitute' kheer mix powder. Journal of Food Science and Technology, 51(10):24042414

Bunkar, D.S., Jha, A., Mahajan, A. and Unnikrishnan, V.S. (2014). Kinetics of changes in shelf life parameters during storage of pearl millet kheer mix and development of a shelf life prediction model. Journal of Food Sciences and Technology, 51(12): 3740-3748

Chakraborty, S.K., Kumbhar, B.K. and Chakraborty, S. (2011). Influence of processing parameters on textural characteristics and overall acceptability of millet enriched biscuits using response surface methodology. Journal of Food Science and Technology, 48: 167-174.

Chandel, G.; Meena, R.K.; Dubey, M. and Kumar, M. (2014). Nutritional properties of minor millets: neglected cereals with potentials to combat malnutrition. Current Science, 107(7): 1109-1111.

Deeth, H.C.; Fitz-Gerald, C.H. and Wood, A.F. (1975). A convenient method for determining the extent of lipolysis in milk. Australian Journal of Dairy 
Technology, 30(3):109-111

Dickinson, W.E. (1958). Kjeldahl Determination of Nitrogen. Analytical Chemistry, 30(5): 992-994.

Gamel, T.H.; Badali, K. and Tosh, S.M. (2013). Changes of $\beta$-glucan physicochemical characteristics in frozen and freeze dried oat bran bread and porridge. Journal of Cereal Science, 58(1): 104-109.

Helland, M.H.; Wicklund, T. and Narvhus, J.A. (2002). Effect of germination time on alpha amylase production and viscosity of maize porridge. Food Research International, 35(2), 315-321.

Henselman, M., Donatoni, S. and Henika, R. (2006). - Use of response surface methodology in the development of high protein bread. Journal of Food Science, 39: 943:946

Keeny, M. and Bassette, R, (1959). Detection of intermediate compounds in the early stages of browning reaction in milk products. J Dairy Sci 42:945-960.

Kadam, B.R., Lembhe, A.F. and Zanjad, P.N. (2011).Formulation of kheer ready-mix based on sensory attributes. Tamilnadu Journal of Veterinary and Animal Sciences, 7(2): 88-93.

Kanu, P.J, Sandy, E.H., Kandeh, B.J., Bahsoon, J.Z. and Huiming, Z. (2009). Production and evaluation of breakfast cereal based porridge mixed with sesame and pigeon peas for adults. Pakistan Journal of Nutrition, 8:13351343.

Khan, M.A., Semwal, A.D., Sharma, G. K. and Bawa, A.S. (2014). Studies on the optimization and stability of instant wheat porridge (Dalia) mix, Journal of Food Science and Technology, 51(6): 1154-1160.

Malathi, D., Thilagavathi, T. and Sindhumathi, G. (2012). Traditional Recipes from Kodo millet, revalorizing small millets. "Enhancing the food and nutritional security of women and children in rain fed regions of South Asia using underutilized species". Post Harvest Technology Centre, Agricultural Engineering College \& Research Institute Tamil Nadu Agricultural University.

Moussa, B., Abdoulaye, T., Coulibaly, O., Baributsa, D. and DeBoer, J.L. (2012). Adoption of on-farm hermetic storage for cowpea in West and Central Africa in 2012. Journal of Stored Products Research, 58: 77-86.

Nicole, M., Fei, H.Y. and Claver, I.P. (2010). Characterization of ready-to-eat composite porridge flours made by soy-maize-sorghum-wheat extrusion cooking process. Pakistan Journal of Nutrition, 9(2): 171-178.

Nishino, T., Shibahara-Sone, H., KikuchiHayakawa, H. and Lshikawa, F. (2000).Transit of radical scavenging activity of milk products prepared by maillard reaction and Lactobacillus caseii strain shirota fermentation through the hamster intestine. J Dairy Sci, 83: 915-922.

Reddy, C.R., Rekha and Vijayalakshmi, G. (1982). Accelerated fermentation of idli batter using soy residue okara. Journal of Food Science and Technology, 48(3): 329-334.

Rhim, J.W., Koh, S. and Kim, J.M. (2011). Effect of freezing temperature on rehydration and water vapor adsorption characteristics of freeze-dried rice porridge. Journal of Food Engineering, 104(4), 484-491.

Rossel, J.B. (1989). Measurement of rancidity In: Rancidity in food (Eds) J.C. Allen \& R.J. Hamilton) Applied Science Publishers, London. Pp. 21-45.

Serrem, C., Kock, H. and Taylor, J. (2011). Nutritional quality, sensory quality and consumer acceptability of sorghum and bread wheat biscuits fortified with 
defatted soy flour. Int. J. Food Sci. Technol. 46: 74-83.

Sudharshana, L., Monteior, P.V. and Ramachandra, G. (1988). Studies on the proteins of kodo millet (Paspalum scrobiculatum). Journal of the Science of Food and Agriculture, 42(4): 315323.

Teangpook, C., Paosangtong, U., Titatarn, Y., Onhem, S. and Puminat, W. (2011). Production and Nutrition of KhiLek (Siamese cassia) Curry from Central Thailand. Kasetsart J. (Nat. Sci.) 45:510 - 520

Van Soest, P.J. and McQueen, R.W.
(1973). The chemistry and estimation of fiber. Proc. Nutr. SOC., 32: 123-130

Weber and Fuller (2006). Millets and their role in early agriculture. Journal Pragdhara, Paper presented in the International Seminar on the "First Farmers in Global Perspective', Lucknow, India, 18-20 January, 2006.

Zeb, A. and Ullah, F. (2016). A simple spectrophotometric method for the determination of thiobarbituric acid reactive substances in fried fast foods. Journal of Analytical Methods in Chemistry, 2016:1-5.

\section{How to cite this article:}

Durga Shankar Bunkar, Pragya Bharti, Kamalesh Kumar Meena, S. K. Goyal and Paswan, V. K. 2020. Studies on the Optimization and Development of Functional Instant Kodo Millet Based Porridge Mix. Int.J.Curr.Microbiol.App.Sci. 9(09): 1462-1480.

doi: https://doi.org/10.20546/ijcmas.2020.909.186 